\title{
Phobic Anxiety and Panic Anxiety: How do They Differ?
}

\author{
BRUCE A. Thyer, Ph.D.* \\ School of Social Work, Florida State University, Tallahassee, FL
}

JoSEPH HiMLE, M.S.W.

Department of Psychiatry, University of Michigan Hospitals, Ann Arbor, MI

\begin{abstract}
Acute anxiety symptoms reported by 20 patients with simple phobia and 20 patients with panic disorder were compared. Panic anxiety symptomatology was commonly rated as more severe in its intensity than that reported by the simple phobics. The pattern of symptoms experienced by the two diagnostic groups shared only $30 \%$ of the variance in symptom rankings. These results suggest that there are both quantitative and qualitative differences between phobic and panic anxiety, and have a bearing on recent diagnostic and etiological formulations of the anxiety disorders.
\end{abstract}

Among the recent developments in the descriptive pathology and etiology of the anxiety disorders has been the distinction made between the so-called phobic disorders (Simple and Social Phobia, Agoraphobia without Panic Attacks) and those anxiety disorders which have their origin in the individual experiencing repeated random episodes of apparently spontaneous panic attacks (SPAs), the diagnoses of panic disorder and agoraphobia with panic attacks (APA, 1980). It is now reasonably well established that the phobic disorders have a mode of onset usually associated with some personal or vicarious traumatic experience involving the individual's anxiety evoking stimulus. In other words, snake phobics frequently report a history of once being terrified by a snake, speech phobics of being humiliated during early efforts at giving a public address, etc. While this mode of onset is clearly not adequate to explain all cases of the phobic disorders, sufficient evidence exists to document this psychosocial etiology for the majority of such patients (Lautch, 1971; Munjack, 1984; Ost \& Hugdahl, 1981: Wolpe, 1981).

For those disorders associated with spontaneous panic attacks, however, the mechanism of onset is less clear. As noted by Freud (1959),

* Address correspondence and reprint requests to Dr. Bruce A. Thyer, School of Social Work. Florida State University. Tallahassee. Florida 32306. 
most agoraphobics give a history of such panic attacks, and the phobic restrictions associated with agoraphobia represent avoidance behavior on the part of the individual who does not want " . . . to be alone or in public places from which escape might be difficult or help not available in case of sudden incapacitation" (APA, 1980, p. 227). This hypothesis is supported by chart review studies which demonstrate that the vast majority of agoraphobics seeking treatment meet the criteria for agoraphobia with panic attacks (Thyer, Parrish, Curtis. Nesse, \& Cameron, 1985), not for agoraphobia without panic attacks, and by the fact that for most cases agoraphobia with panic attacks the onset of SPAs precedes the onset of phobic avoidance behaviors (Sheehan, Ballenger, \& Jacobson, 1981: Thyer \& Himle, 1985).

A further distinction between agoraphobia with panic attacks and panic disorder, compared to the phobic disorders, is that most patients with the former conditions do not report a history of traumatic experience to be associated with the onset of their fears. According to Mathews, Gelder, and Johnston (1981) “... agoraphobics cannot as a rule recall either any event that provoked intense fear or any repeated fearful events that occurred in the circumstances that they subsequently came to avoid" (p. 41). Likewise, Tearnan, Telch, and Keefe (1984), in their recent extensive review of the etiology of agoraphobia, failed to find adequate evidence in support of a traumatic conditioning hypothesis. Although the DSM-III narrative commentary suggests that Separation Anxiety Disorder of Childhood and sudden object loss apparently predispose to the development of both agoraphobia or panic disorder, this separation anxiety hypothesis is not adequately supported by past research (Tearnan et al., 1984), and controlled studies suggest that it may even be false (Thyer, Nesse, Cameron, \& Curtis, 1985: Thyer, Nesse, Curtis, \& Cameron, 1986).

In recent years a number of clinical researchers, primarily biological psychiatrists, have hypothesized that SPAs are the result of a metabolic defect and not necessarily related to intrapersonal psychopathology. Evidence for this view may be summarized along several lines: in the specific vulnerability of agoraphobic and panic disorder patients to the artificial induction of panic attacks via lactate challenge testing (Sheehan. Carr. Fishman, Walsh, \& Peltier-Saxe, 1985) [Margraf, Ehlers, and Roth (1986) have recently challenged this evidence]; in controlled family prevalence studies suggesting a genetic vulnerability to panic attacks (Tearnan. Telch, \& Keefe, 1984); in the greater than expected concordance between the occurrence of panic attacks and the presence of mitral valve prolapse (Crowe, 1985); and in the temporary amelioration of panic attacks during treatment with tricyclic antidepressants, monoamine oxidase inhibitors, and the triazolobenzodiazepene alprazolam (Leibowitz, 1985; Sheehan, 1985). A thorough review of the above evidence is found in Curtis. Thyer. and Rainey (1985).

On the basis of such findings, Sheehan and associates (Carr \& Sheehan, 1984: Sheehan, 1982; Sheehan. Ballenger, \& Jacobson. 1980. 
1981: Sheehan \& Sheehan. 1982a, 1982b) have proposed revising the diagnostic nomenclature of the anxiety disorders by postulating that there are only two major anxiety syndromes, exogenous anxiety, corresponding to the DSM-III categories of simple and social phobia, agoraphobia without panic attacks, and post-traumatic stress disorder, all caused by psychosocial etiologies, and endogenous anxicty, corresponding to the DSM-III diagnoses of agoraphobia with panic attacks and panic disorder. It is not clear where the current diagnoses of Generalized Anxiety Disorder (in the absence of a history of SPAs) or Obsessive Compulsive Disorder would fit into this proposed schema. Proposed revisions of the DSM-III anxiety disorders criteria are somewhat in accord with Sheehan's suggestions (Spitzer \& Williams, 1985), suggesting the influence these views are having on contemporary diagnostic and etiological formulations. Cohen, Barlow, and Blanchard (1985) note this “.. growing belief among some researchers that panic attacks and accompanying anticipatory anxiety are separate and distinct aspects of anxiety disorders" (p. 96) and that ". . . it is as yet unclear if panic attacks represent the peak of a quantitative increase in anxiety, or a qualitatively different phenomenon" (p. 97). Zitrin, Woerner, \& Klein (1981) are among those in favor of viewing phobic anxiety and panic anxiety as separate disorders, whereas others. such as Greist, Jefferson, and Marks contend that "... as far as we can tell the feelings are similar whether the anxiety (or panic) is spontaneous or phobic" (1986, p. 3). Adequate data does not yet exist to clearly refute or support Sheehan's dichotomy.

The detection of clinically significant and statistically meaningful differences in the symptomatic presentations of patients is a well established method for distinguishing between disorders (e.g., Cameron, Thyer, Nesse, \& Curtis, 1986; Thyer, Himle, Curtis, Cameron, \& Nesse, 1985). One test of the hypothesis that phobic anxiety and panic anxiety are characteristics of different disorders is to examine the symptomatology reported by patients suffering from exogenous anxiety (e.g., simple phobia), and then comparing this symptom profile with that obtained from a sample of patients with presumptive endogenous anxiety (e.g. . panic disorder). The study described below employed this method to examine the symptomatic differences occurring between simple phobic and panic disorder patients.

\section{METHOD}

\section{Subjects}

Our sample consisted of individuals who had sought treatment at the Anxiety Disorders Program at the University of Michigan Hospitals between 1980 and 1985. We randomly selected patient records for 20 individuals ( 13 female. 7 male) diagnosed as having panic disorder to serve as our sample of individuals with so-called endogenous anxiety. These pa- 
tients had a mean age (and standard deviation) of 38.6 years $(9.7)$. Our randomly selected sample of patients with exogenous anxiety consisted of 20 simple phobics ( 15 female, 5 male) who had a mean age of 36.7 years (8.9). Five of our simple phobics were single, 11 were married, and four were divorced. Eighteen of the simple phobics were white, one was black and one was oriental. Two of our panic disorder patients were single, 15 were married, and three were divorced. Nineteen of the panic disorder patients were white and one was black. Patients in each diagnostic group had a mean of 14 years of education. The mean age of onset reported by the patients with panic disorder for their disorder was 30.2 years (10.6); the corresponding figure for simple phobia was 15.1 years (10.6). These findings regarding a differential age of onset for simple phobia and panic disorder were congruent with our earlier study of this topic (Thyer, Parrish, Curtis, Cameron, \& Nesse, 1985). The primary anxiety evoking stimulus for each of the 20 simple phobics was as follows: snakes $(n=4)$, flying $(n=4)$, heights $(n=3)$, spiders $(n=2)$, injections $(n=2)$, and pill swallowing, food poisoning, birds, darkness and flying insects, $(n=1)$.

\section{Procedure}

As a part of our clinic's intake and evaluation process, and prior to a detailed diagnostic interview with a clinician skilled in the use of the DSM-III criteria, each patient completed a comprehensive questionnaire packet containing, among other items, the Cameron-Nesse Anxiety Symptoms Questionnaire (ASQ), an inventory listing 55 symptoms commonly associated with states of anxiousness (described in Cameron, Thyer, Nesse, \& Curtis, 1986). Each patient had indicated the degree to which they had experienced the symptom listed on the ASQ using a five point rating scale $(0=$ none; $4=$ very severe). Panic disorder patients completed the ASQ with respect to what they felt during a typical spontaneous panic attack. Simple phobics completed the ASQ items with reference to how they felt when confronting their individual anxiety evoking stimulus (most often a small animal). Our preliminary report employing other patient samples found the ASQ to demonstrated discriminant validity with respect to the diagnostic clusters predicted by Sheehan and others: Panic disorder, agoraphobia with panic attacks, and generalized anxiety disorder symptoms tended to cluster together, and to be significantly different from the symptom patterns reported by simple and social phobics.

\section{RESULTS}

The mean score (and standard deviation), by diagnostic group, for each of the 55 ASQ items is displayed in Table 1. As can be seen, panic disorder (endogenous anxiety) patients consistently rated the intensity of 
TABLE 1

MEAN Symptom Ratings and ITEM Rankings by Diagnostic Group

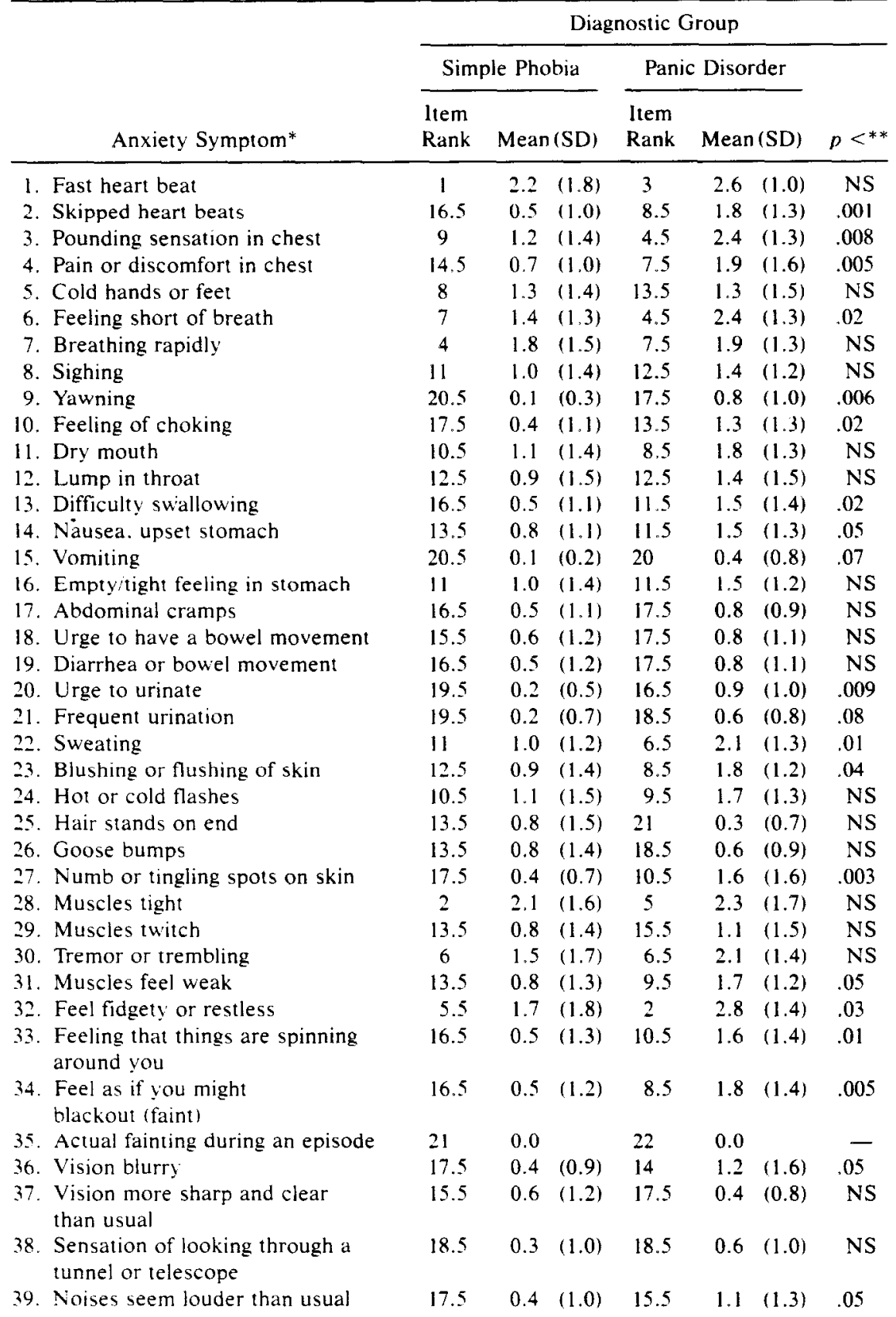


TABLE 1 - Continued

\begin{tabular}{|c|c|c|c|c|c|}
\hline \multirow[b]{3}{*}{ Anxiety Symptom* } & \multicolumn{5}{|c|}{ Diagnostic Group } \\
\hline & \multicolumn{2}{|c|}{ Simple Phobia } & \multicolumn{2}{|c|}{ Panic Disorder } & \multirow[b]{2}{*}{$p<* *$} \\
\hline & $\begin{array}{l}\text { Item } \\
\text { Rank }\end{array}$ & Mean (SD) & $\begin{array}{l}\text { Item } \\
\text { Rank }\end{array}$ & Mean (SD) & \\
\hline $\begin{array}{l}\text { 40. Feeling that people are looking } \\
\text { at you }\end{array}$ & 18.5 & $0.3 \quad(0.9)$ & 12.5 & $1.4 \quad(1.6)$ & .01 \\
\hline 41. Walking seems unsteady & 16.5 & $0.5 \quad(1.1)$ & 11.5 & $1.5 \quad(1.1)$ & .006 \\
\hline $\begin{array}{l}\text { 42. Feeling of doom-As if something } \\
\text { terrible will happen }\end{array}$ & 5.5 & $1.7 \quad(1.8)$ & 1 & $2.9 \quad(1.2)$ & .01 \\
\hline 43. Feel as if you were dying & 15.5 & $0.6 \quad(1.1)$ & 7.5 & $1.9 \quad(1.6)$ & .004 \\
\hline 44. Thinking seems confused & 12.5 & $0.9 \quad(1.4)$ & 9.5 & $1.7(1.7)$ & .08 \\
\hline 45. Feel as if you were "Going Crazy" & 14.5 & $0.7 \quad(1.4)$ & 4.5 & $2.4 \quad(1.5)$ & .001 \\
\hline 46. Things seem unreal & 20.5 & $0.1 \quad(0.4)$ & 10.5 & $1.6 \quad(1.6)$ & .0003 \\
\hline $\begin{array}{l}\text { 47. Feeling of being detached } \\
\text { from your body }\end{array}$ & 16.5 & $0.5 \quad(1.3)$ & 13.5 & $1.3(1.6)$ & NS \\
\hline 48. Feel like running & 3 & $2.0 \quad(1.8)$ & 7.5 & $1.9 \quad(1.6)$ & NS \\
\hline $\begin{array}{l}\text { 49. Feel as if you might freeze or } \\
\text { be unable to move }\end{array}$ & 12.5 & $0.9 \quad(1.6)$ & 16.5 & $0.9 \quad(1.1)$ & NS \\
\hline $\begin{array}{l}\text { 50. Feel as if you might suddenly } \\
\text { do something uncontrolled }\end{array}$ & 14.5 & $0.7 \quad(1.1)$ & 9.5 & $1.7 \quad(1.7)$ & .03 \\
\hline 51. Headache & 10.5 & $1.1 \quad(1.2)$ & 15.5 & $1.1 \quad(1.4)$ & NS \\
\hline 52. Mind goes blank & 17.5 & $0.4 \quad(0.6)$ & 16.5 & $0.9(1.2)$ & .06 \\
\hline 53. Voice cracks or wobbles & 10.5 & $1.1 \quad(1.4)$ & 16.5 & $0.9\langle 1.1\}$ & NS \\
\hline $\begin{array}{l}\text { 54. Difficulty in forming sounds } \\
\text { and speaking normally }\end{array}$ & 13.5 & $0.8 \quad(1.5)$ & 15.5 & $1.1 \quad(1.6)$ & NS \\
\hline $\begin{array}{l}\text { 55. Objects appear to be distorted or } \\
\text { to move when they really don't }\end{array}$ & 17.5 & $0.4 \quad(1.1)$ & 19 & $0.5 \quad(1.1)$ & NS \\
\hline
\end{tabular}

* Rating scale: $z$ ero $=$ none: $1=$ mild: $2=$ moderate: $3=$ severe: $4=$ very severe

** Two-tailed $t$-test.

the symptoms they experienced during a typical spontaneous panic attack as more severe than that experienced by the simple phobics on 46 of the 55 symptoms. Of these 46 differences, 23 were statistically significantly different $(p<.05)$ and four displayed a statistical trend $(p<.10)$. The simple phobics reported more intense symptoms on five of the ASQ items, but none of these differences exceeded chance expectations. Four ASQ symptoms were rated as equally severe by the two groups. These results argue in favor of the view that the symptoms experienced during panic anxiety are quantitatively more severe than the phenomenology of phobic anxiety.

A Spearman rank-order correlation coefficient was calculated on the rankings of the symptom severity ratings provided by the two patient groups (rho $=.55 ; p<.01$ ). This correlation, while statistically significant, indicales that the anxiely symptomatology experienced by panic disorder and simple phobic patients shared only $30 \%$ of the variance in ranked reported symptoms. This finding suggests that there are mean- 
ingful qualitative, as well as quantitative, differences occurring among patients experiencing either phobic anxiety or panic anxiety. In other words, the pattern of type of anxiety symptomatology reported by the two groups appears to be fairly distinct.

\section{DISCUSSION}

These results support the hypothesis that phobic anxiety and panic anxiety represent separate and reasonably distinct subjectively experienced phenomena, and are congruent with newer etiological speculations and nosological formulations which postulate that the anxiety disorders may be heuristically divided into two broad categories, labeled exogenous and endogenous anxiety. Given our relatively small sample size, and the fact that alternative interpretations of our data may be possible, this conclusion remains tentative.

A limitations in the present study is a sole reliance upon client selfreport to assess anxiety symptomatology. In part, this is necessary since many of the symptoms of anxiety are private events, feelings or perceptual experiences which may only be accessed through patients' verbal or written behavior. Contemporary research examining the psychoneuroendocrinology of spontaneous panic attacks (Cameron, Lee, Curtis, \& McCann, 1985), and that associated with simple phobic reactions (Nesse, Curtis, Thyer, McCann, Huber-Smith, \& Knopf, 1985; Thyer \& Mathews, 1986) may provide further information as to the similarities and differences of the signs and symptoms existing between the anxiety disorders. Previously, such studies have employed patients labeled with a single diagnostic category (e.g., panic disorder or simple phobia); controlled comparative experiments on the biological parameters of anxiety associated with the various diagnoses are now indicated.

None of our forty patients reported a history of fainting, either during a SPA or when confronting their anxiety evoking stimulus. Such a fainting reaction is an exaggerated vasuvagal reflex (Thyer \& Curtis, 1985 ), and past research has suggested that fainting responses are selectively associated with fears to blood, injury, or illness (BII) (Curtis \& Thyer, 1983: Thyer, Himle \& Curtis, 1985). Since none of our patients complained of BIl phobia. the present data lend further support to the hypothesis of a selective association between such fears and a fainting reaction. Although panic disorder patients may feel as if they may faint during an SPA (see item 34 in Table 1), the probability of an actual loss of consciousness appears low.

\section{REFERENCES}

American Psychiatric Association. (1980). Diagnostic and statistical manual of mental disorders (3rd ed.). Washington. DC: Author.

Cameron. O. G.. Lee. M. A.. Curtis, G. C. \& McCann, D. S. (1985). Psychobiologic changes during "spontaneous" panic. Psychosomatic Medicine, 47, 308. 
Cameron, O. G., Thyer, B. A., Nesse, R. M., \& Curtis. G. C. (1986). Symptom profiles of DSM-III anxiety disorders. American Journal of Psychiatry, 143, 1132-1137.

Carr, D. B., \& Sheehan, D. V. (1984). Panic anxiety: A new biological model. Joumal of Clinical Psychiatry, 45, 323-330.

Cohen, A. S., Barlow. D. H., \& Blanchard. E. B. (1985). Psychophysiology of relaxationassociated panic attacks. Journal of Abnormal Psychology, 94, 96-101.

Crowe, R. R. (1985). Mitral valve prolapse and panic disorder. In G. C. Curtis. B. A. Thyer, \& J. M. Rainey (Eds.). Psychiatric clinics of North America: Anxiety disorders (pp. 63-71). Philadelphia: Saunders.

Curtis, G. C., \& Thyer, B. A. (1983). Fainting on exposure to phobic stimuli. American Journal of Psychiarry, 140, 771-774.

Curtis, G. C., Thyer, B. A., \& Rainey, R. M. (Eds.). (1985). Psychiatric clinics of North America: Anxiety disorders. Philadelphia: Saunders.

Freud, S. (1959), Obsessions and phobias. In J. Riviere (Trans.). Sigmund Freud collected papers (Vol. 1). New York: Basic Books. (Original published in 1895).

Greist. J. H., Jefferson, J. W., \& Marks, I. M. (1986). Anxiety and its reatment. Washington, D.C.: American Psychiatric Press.

Lautch, H. (1971). Dental phobia. British Journal of Psychiatry, 119, $151-158$.

Leibowitz, M. R. (1985). Imipramine in the treatment of panic disorder and its complications. In G. C. Curtis, B. A. Thyer, and J. M. Rainey (Eds.). Psychiatric clinics of North America: Anxiety disorders (pp. 37-47). Philadelphia: Saunders.

Margraf, J., Ehlers, A., \& Roth, W. T. (1986). Sodium lactate infusions and panic attacks: A review and critique. Psychosomatic Medicine, 48, $25-51$.

Mathews, A. M., Gelder, M. G., \& Johnston, D. W. (1981). Agoraphobia: Nature and treatment. New York, Guilford.

Munjack, D. J. (1984). The onset of driving phobias. Journal of Behavior Therapy and Experimental Psychiatry, 15, 305-308.

Nesse, R. M., Curtis, G. C., Thyer, B. A., McCann, D. S., Huber-Smith. M.. \& Knopf. R. F. (1985). Endocrine and cardiovascular responses during phobic anxiety. Psychosomatic Medicine, 47, 320-332.

Ost, L., \& Hugdahl, K. (1981). Acquisition of phobias and anxiety response patterns in clinical patients. Behaviour Research and Therapy, 19, 439-447.

Sheehan, D. V. (1982). Panic attacks and phobias. New England Journal of Medicine. 307, $156-158$.

Sheehan, D. V. (1985). Monoamine oxidase inhibitors and alprazolam in the treatment of panic disorder and agoraphobia. In G. C. Curtis. B. A. Thyer. \& J. M. Rainey (Eds). Psychiatric clinics of North America: Anxiety disorders (pp. 49-62). Philadelphia: Saunders.

Sheehan, D. V., Ballenger. J., \& Jacobson, G. (1980). Treatment of endogenous anxiety with phobic, hysterical, and hypochondriacal symptoms. Archives of General Psychiatry, 37, $51-59$.

Sheehan, D. V., Ballenger, J., \& Jacobson, G. (1981). Relative efficacy of monoamine oxidase inhibitors and tricyclic antidepressants in the treatment of endogenous anxiety. In D. F. Klein \& J. Rabkin (Eds.), Anxiety: New research and changing concepts (pp. 47-67). New York: Raven Press.

Sheehan, D. V., Carr, D. B., Fishman, S. M., Walsh, M. M., \& Peltier-Saxe, D. (1985). Lactate infusion in anxiety research: Its evolution and practice. Journal of Clinical Psy. chiatry, 46, 158-165.

Sheehan, D. V., \& Sheehan, K. H. (1982a). The classification of anxiety and hysterical states. Part I. Historical review and empirical delineation. Journal of Clinical Psychopharmacology, 2, 235-243.

Sheehan, D. V., \& Sheehan, K. H. (1982b). The classification of anxiety and hysterical 
states. Part II. Toward a more heuristic classification. Journal of Clinical Psychopharmacology, 2, 386-393.

Spitzer. R. L.. \& Williams. J. B. W. (1985). Proposed revisions in the DSM-Ill classification of anxiety disorders based upon research and clinical experience. In A. H. Tuma \& J. D. Maser (Eds.). Anxiety and the anxiety disorders (pp. 759-775). Hillsdale. NJ: Erlbaum.

Tearnan, B. H.. Telch, M. J., \& Keefe, P. (1984). Etiology and onset of agoraphobia: A critical review. Comprehensive Psychiatry, 25, 51-62.

Thyer. B. A.. \& Curtis. G. C. (1985). On the diphasic nature of vasovagal fainting associated with blood-injury-illness phobia. Pavlovian Journal of Biological Science. 20, 84-87.

Thyer, B. A., \& Himle, J. (1985). Temporal relationship between panic attack onset and phobic avoidance in agoraphobia. Behaviour Research and Therapy, 23, 607-608.

Thyer, B. A.. Himle, J., \& Curtis, G. C. (1985). Blood-injury-illness phobia: A review. Journal of Clinical Psychology, 41, 451-459.

Thyer, B. A.. Himle. J., Curtis, G. C., Cameron, O. G., \& Nesse, R. M. (1985). A comparison between panic disorder and agoraphobia with panic attacks. Comprehensive Psychiatry, 26, 208-214.

Thyer. B. A., \& Mathews. J. (1986). The effect of phobic anxiety on plasma beta-endorphin: A single-subject experiment. Behaviour Research and Therapy, 24, 237-241.

Thyer, B. A., Nesse, R. M., Cameron, O. G., \& Curtis. G. C. (1985). Agoraphobia: A tes1 of the separation anxiety hypothesis. Behaviour Research and Therapy, 23, 75-78.

Thyer. B. A.. Nesse. R. M., Curtis, G. C., \& Cameron, O. G. (1986). Panic disorder: A test of the separation anxiety hypothesis. Behaviour Research and Therapy, 24, 209-211.

Thyer, B. A., Parrish. R. T., Curtis. G. C., Nesse. R. M.. \& Cameron, O. G. (1985). Ages of onset of DSM-IH anxiety disorders. Comprehensive Psychiatry, 26, 113-122.

Wolpe, J. (1981). The dichotomy between classical conditioning and cognitively learned anxiety. Journal of Behavior Therapy and Experimental Psychiatry, 12, 35-42.

Zitrin, C. M., Woerner. M. G.. \& Klein. D. F. (1981). Differentiation of panic anxiety from anticipatory anxiety and avoidance behavior. In D. F. Klein \& J. Rabkin (Eds.), Anxiety: New research and changing concepts (pp. 27-46). New York: Raven Press. 